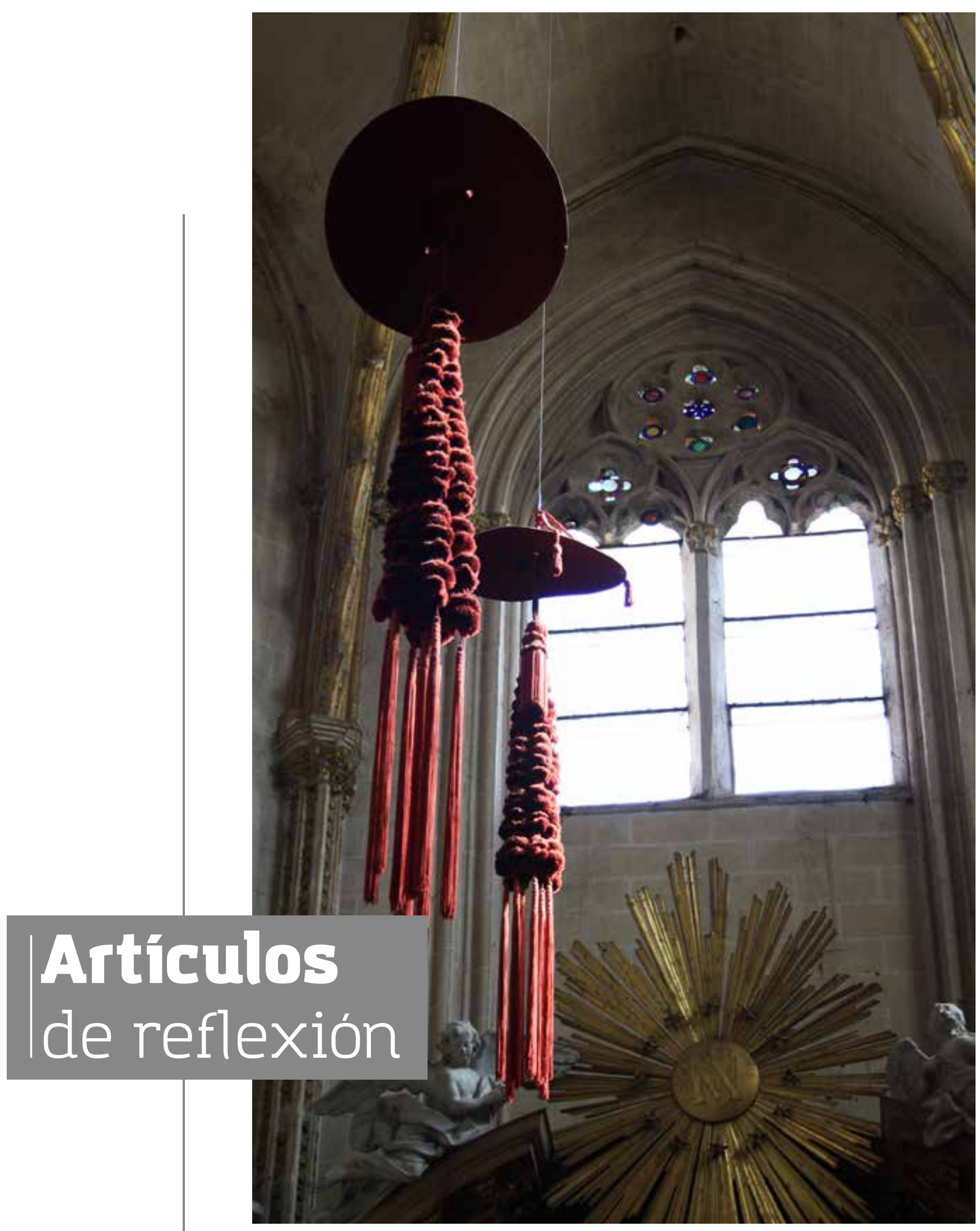




\section{Ficción, crisis y futuro: el caso de Interestelar}

\section{Fiction, crisis and future: Interstellar's case}

"Only if we imagine that the planet has a future, after all, are we likely to take responsibility for it".

Garrard (2012)

https://doi.org/10.18566/comunica.n45.a04

Recibido: 19 de abril de 2021

Aceptado: 31 de mayo de 2021

\section{Resumen}

En este artículo se toman ideas del ecocriticismo, una corriente de teoría literaria, para examinar el largometraje Interestelar, de Christopher Nolan, como un documento cultural que usa diferentes instrumentos narrativos para exponer sistemas de valores en tensión ante situaciones ambientales extremas, como lo es la crisis climática actual. Se examina cómo las tensiones se expresan a través del uso de la tecnología, la noción del papel de la humanidad en relación con su entorno y la concepción del futuro. Se explora la perspectiva cornucopiana presente en la película, así como la romantización que sugiere de la colonización y la conquista de nuevos mundos. Al final se concluye cuáles son los elementos culturales que se resaltan en la película y que proyectan un discurso concreto sobre el futuro.

\section{Abstract}

This article takes literary theory as a basis to formulate its thesis, more specifically, it departs from the line of thought known as ecocriticism to examine the film Interstellar by Christopher Nolan. This movie is taken as a cultural document that uses diverse narrative tools to expose the tensions generated amongst diverse systems of values when facing extreme environmental situations. The film's cornucopian perspective, the romanticization of the colonization, the conquest, and the explorer will be explored in the present analysis. Last, the article concludes by summarizing the cultural aspects that are highlighted and that serve in the construction of a discourse and a particular projection of the future. comunicación

número 45

Julio - diciembre

2021 | pp.52-63

\section{Juanita}

Álvarez Jaramillo

Antropóloga egresada de la Universidad de Antioquia.

MSc con énfasis en Ecología Humana de la Universidad de Lund, Suecia.

Investigadora en el proyecto Desarrollo de una estrategia de alistamiento para la consolidación de Bogotá Región, como epicentro de paz y reconciliación, a través de la implementación del Acuerdo de Paz, ejecutado por Procamsu (Asociación de Productores Rurales de Sumapaz).juanaalvarezjllo@ gmail.com

Palabras clave Crisis climática, Futuro, Tecnología, Ficción, Ecocriticismo.

\section{Keywords}

Climate crisis, Future, Technology, Fiction, Ecocriticism. 


\section{Introducción}

Este ensayo explora el papel de la ciencia ficción en la película Interestelar (2014), de Christopher Nolan, como un texto donde se revelan elementos culturales en la imaginación del futuro y el entendimiento de la crisis climática. Para este análisis me apoyo en las ideas del ecocriticismo, corriente que aparece en la primera página del libro escrito por el profesor de literatura inglesa Greg Garrard (2012) y que es descrita como una línea de pensamiento dedicada a estudiar las diversas formas de producción cultural usadas para representar las relaciones existentes entre los seres humanos y el medioambiente. En este caso, la película muestra escenarios de crisis ambiental y su consecuente superación a través de la colonización del espacio exterior. La premisa básica de esta obra fílmica se teje haciendo uso de diferentes narrativas en torno a la crisis ambiental, actitudes frente a ella y frente al planeta que habitamos. De forma más general, este análisis se enmarca en la idea de que el futuro es un hecho cultural; por lo tanto, analizar esta película tiene como intención evidenciar y cuestionar ideas implícitas que apelan y conversan con las formas en que entendemos la actual crisis climática, además de entender la imaginación como una fuerza activa en la producción de futuro.

\section{El futuro como hecho cultural}

El futuro como hecho cultural es el título de la obra del antropólogo indio Arjun Appadurai (2013), en la cual aboga por una antropología del futuro como la búsqueda y el estudio de "las formas en que diferentes sociedades humanas organizan el futuro como horizonte cultural" y de cómo se constituyen las diversas ideas de bienestar humano y del buen vivir a partir de elementos que definen, desde construcciones culturales, qué es posible y qué no lo es (Appadurai, 2013). Así se propone aquí la ciencia ficción como un género narrativo que expone, entre otras cosas, representaciones culturales sobre el futuro, a través de ideas, relaciones, elementos y debates reales ya presentes, así como trazos de las acciones posibles y valores por privilegiar en el porvenir.

Según Buschman y Oels (2018), se puede definir un discurso como un sistema de significados compartidos que es reproducido en prácticas sociales y que tienen consecuencias concretas; es decir, los discursos no solo describen o exponen una visión sobre el mundo, sino que son parte de su producción (Hajer, 1995, citado en Buschman y Oels, 2018)1. En este sentido, los discursos que abordan el futuro, prediciéndolo, imaginándolo, también tienen una carga ideológica y un poder simbólico que pueden ser usados para argumentar a favor o en contra de prácticas o posiciones

1 Traducción propia. 
políticas actuales. Sin embargo, los elementos que constituyen y alimentan esos discursos son determinados por el contexto cultural en el que emergen; aquello que es o que se ve como lo que puede ser, lo posible, varía de un lugar a otro, así como el entendimiento de su gravedad. La investigadora ambiental Karin Skill (2011) sugiere que a pesar de la objetividad de las problemáticas ambientales que constituyen la actual crisis climática, se necesitan narrativas construidas socialmente, es decir, que transmitan una noción de riesgo y peligro culturalmente significativa para provocar respuestas y acciones en los diferentes grupos humanos a los que apela.

Esta noción de riesgo y peligro no solo se desprende de los intereses que se ven amenazados en cada grupo humano, sino también a partir de cierta verosimilitud en las causas y consecuencias que rodean los eventos ambientales. Por ejemplo, la socióloga Marie Norgaard (2011) expone en su libro Viviendo en negación cómo una población noruega, no obstante tener abundante información acerca del cambio climático e incluso ver sus efectos en el día a día, es reticente a tomar acciones, y algunos, aun, resaltan los cambios como aspectos positivos; por ejemplo, el prolongamiento de épocas con temperaturas más altas, menos hielo (que suele impedir ciertas actividades de recreación), entre otros que son identificados como ventajas por la población.

Appadurai (2013) propone el estudio del futuro partiendo de la imaginación, la aspiración y la anticipación como los fundamentos sociales que lo constituyen como un hecho cultural. Este tipo de estudios tendrían que incluir las producciones culturales como textos que juegan un papel fundamental en la organización de ese futuro. No solo introducen ideas de lo que es posible, sino, tal vez más importante, introducen al público a ciertas actitudes que se toman frente a eventos climáticos extremos; en el caso de Interestelar, el apocalipsis no se presenta como un evento angustioso o traumático, sino como un suceso al cual las personas responden con estoicismo e, incluso, optimismo.

Estas tres dimensiones (la imaginación, la aspiración y la anticipación) se expresan de alguna forma en la película. Interestelar es un relato colectivo, que en su ficción recoge y apela a normas, creencias y valores, de los que cada espectador echa mano, y que no hace eco en el vacío, sino que habla de un pasado y en un contexto cultural donde se cimienta para crear imágenes e ideas sobre el futuro. Así como los economistas forman parte de la construcción social del futuro con sus proyecciones, modelos y riesgos (Appadurai, 2013), los artistas y las producciones culturales también participan en esa construcción (particularmente desde la ciencia ficción) a partir de imágenes y repertorios de realidades e historias alternas. 
En un documento como Interestelar se recogen elementos de un imaginario social, al tiempo que se toman conocimientos científicos para representar cierta visión de la humanidad y evocar un futuro, no muy distante, cuyos rasgos podemos vislumbrar. De igual forma, la trama se desarrolla desde una clara política de la esperanza que parte de cómo se imagina el director que los seres humanos actuarían para superar las necesidades que se les imponen en un mundo postapocalíptico. Tal cual lo describe Appadurai (2013, pp. 282-283), la capacidad de aspiración es la dimensión política de la imaginación, las formas prácticas o concretas para orientar a diferentes actores sociales en la satisfacción de sus necesidades y que tienden a ser más desarrolladas en comunidades más adineradas. A continuación, sigo exponiendo la dimensión de la anticipación, que en la película reside en lo que se considera una crisis dentro de una realidad donde la Tierra se ha vuelto un lugar inhóspito para la vida humana.

\section{Crisis}

La crisis en Interestelar se presenta en un mundo postapocalíptico. La acción humana ha llevado al planeta a un punto de quiebre, de enfrentamientos por recursos que ya forman parte del pasado y apenas son mencionados en la historia. Aparece, entonces, la narrativa de un apocalipsis desmitificado, donde la vida de abundancia en los suburbios estadounidenses se acaba y es rememorada con nostalgia, pero al mismo tiempo (presentando el carácter estoico de los personajes) intentan reproducirla bajo las condiciones actuales. Por ejemplo, vemos a los protagonistas en un partido de béisbol, comiendo crispetas en vez de perros calientes, que era el bocadillo tradicional para ese tipo de eventos; momentos después, una alarma anuncia una tormenta de arena causada por la erosión del suelo; los asistentes al juego se levantan sin afán y sin sorpresa para evacuar el lugar como una rutina, lo cual le sugiere al espectador que esta es la nueva realidad a la que está acostumbrada la gente en el futuro que nos presenta. Si bien en Interestelar la crisis no reside en la amenaza de un apocalipsis por el deterioro ambiental, es este el que introduce las condiciones de escasez y las limitaciones que forman la crisis en la narrativa de la película.

La crisis reside en la creciente tensión entre la continuidad de vivir en un planeta con altos niveles de erosión, polución, pérdida de biodiversidad y, por otra parte, mantener el estilo de vida americano. En la historia, las dificultades de la familia protagonista no se traducen en hambre, desplazamiento o tiranía, como en otras películas distópicas que exploran temas similares (Los hijos del hombre, de Alfonso Cuarón). Por el contrario, la familia Cooper sigue manejando una camioneta pick-up (que no debe ser muy eficiente en el uso de gasolina y emisiones) y sigue viviendo en 
una granja con un monocultivo de maíz que parece emplear métodos industriales.

La primera parte de la película consiste en una presentación de símbolos que evocan rasgos identitarios estadounidenses, pero en estado de decadencia. La crisis se hace evidente en la historia cuando se sugiere el final de esos símbolos; la escena del partido de béisbol, de hecho, alude a esto, y también lo hace el estancamiento laboral del protagonista, lo que avisa sobre el fin de la movilidad social, históricamente ligada a la idea de un proyecto de vida en los Estados Unidos. Más adelante se muestra que las colonias espaciales, en vez de ser habitadas densamente por comunidades que se reúnen y se mezclan diversas culturas del mundo, se asemejan más bien a un suburbio estadounidense, donde las viviendas no se adaptan al espacio disponible, sino al contrario: el espacio se adapta al estilo de las viviendas, que bien podría ser un paisaje de los años 50 en Estados Unidos, con la diferencia de que los barrios se doblan sobre sí mismos y en vez del cielo encima de las casas, el espectador se encuentra con otro barrio que mira bocabajo y se impone como una pared. ${ }^{2}$

Una escena que expone muy bien este punto es cuando Cooper, el padre, es llamado ante los supervisores de su hija en el colegio. En el lapso de esta conversación, los profesores terminan minimizando los méritos de su hijo mayor, limitando su libertad de elegir la profesión que quiera y negando el aterrizaje del hombre en la Luna y los avances tecnológicos relacionados con la victoria de Estados Unidos en la carrera espacial; finalmente, se evidencia en esta escena el autoritarismo creciente, basado en el control y la censura del Estado sobre los rumbos de la vida privada de sus ciudadanos. Esta escena muestra el ascenso de los valores contrarios a la libertad individual, el pequeño Estado con su tradición de laissez-faire y el papel protagónico de Estados Unidos en la escena mundial.

En otras palabras, la crisis, la tragedia real que se plantea en Interestelar, no es la pérdida de un mundo natural ni tampoco la necesidad de mantener la sociedad humana en el planeta, sino la amenaza particular de perder los estándares y valores que se relacionan con el modo de vida norteamericano. Otro personaje que sirve para enfatizar este mismo punto es el hijo mayor del protagonista, quien con el tiempo representa el apego irracional y la territorialidad como un comportamiento obstinado ante los ojos de su padre. Nuestro protagonista, Cooper, con su partida y su tarea de salvar a la población humana de la escasez renuncia a su hijo (quien podría representar con facilidad la Tierra, o la territorialidad); pero pareciera que la renuncia a la relación con su hija es menos definitiva. Se nos muestran interacciones mucho más profundas con ella, quien representa la exploración, el desarrollo y el pensamiento científico, y su comunicación pasa a un plano sobre-natural
2 https://interstellarfilm fandom.com/wiki/Cooper_ Station 
para ilustrar dicha continuidad. Esto se expresa, por ejemplo, cuando Murph (la hija) piensa que los códigos en clave morse eran la obra de un fantasma, cuando en realidad se trataba del protagonista comunicándose a través de la fuerza de gravedad con su hija en el pasado.

Esta renuncia de una vida con su familia en la Tierra y su sacrificio por la especie humana pueden ser entendidos como una referencia a la figura de Jesús en el cristianismo. ${ }^{3}$ Esta interpretación refuerza ese ethos de libertad estadounidense, que va ligado a la figura de los exploradores, conquistadores, hombres de acción, y al mismo tiempo se distancia del arraigo, la territorialidad como una actitud pasiva y personificada por un tipo obsesivo (en este caso, su hijo mayor), que, como en el mito de Sísifo, sabe que su suelo está condenado a la esterilidad y aun así siembra, trabaja el campo y se niega a dejar la casa familiar.

Como contraparte de Interestelar se podría mencionar la película Ad astra, dirigida por James Gray en 2019. A diferencia del romanticismo de Interestelar, donde se nos sugiere un nuevo comienzo al colonizar otros planetas, Ad astra plantea su trama a partir de una continuación de las mismas relaciones sociales que se dan en el planeta Tierra y que incluyen la persistencia de los ciclos de crisis. Esta idea se presenta, por ejemplo, cuando se muestra un turismo masivo a la Luna; instalaciones no muy diferentes a los aeropuertos actuales, las mismas ventas de aerolíneas que se trasladan de los aviones a los cohetes y niños que se toman fotos con imágenes de alienígenas como suvenir. Pero es tal vez más diciente la presencia de piratas en la Luna; cuando el protagonista debe desplazarse en carro de un lugar a otro, el espectador se entera de que no solo industrias como el turismo se han expandido al espacio, sino también otras relacionadas con prácticas extractivistas; además, las economías ilegales y los conflictos geopolíticos han escalado al espacio exterior.

Este evento, centrado en un encuentro con piratas lunares, es uno de los instrumentos narrativos que dispersan la ilusión de un nuevo comienzo en el espacio, en un nuevo mundo, que en Interestelar se hace patente con la refundación de la humanidad, siendo la pareja de astronautas norteamericanos los nuevos Adán y Eva. ${ }^{4}$ El mensaje de Ad astra es contrario en cuanto que las relaciones de parentesco, sociales, la nostalgia o la necesidad psicológica de lo terrenal se sobreponen al espíritu explorador y de trascendencia; el planteamiento que sugiere es, más bien, que las crisis y los problemas ambientales irán a donde sea que vayan los humanos, pero la forma y la profundidad que tomen dependerá aún de la acción humana.
3 Hay un análisis más profundo de este aspecto de la película en el canal de divulgación filosófica Wisecrack: https://www.youtube.com/ watch? $v=f 1 Z C f m j z U Z M$

4 Este punto también se plantea en el análisis de Wisecrack. 


\section{Apropiación como solución}

Aunque Interestelar presenta los límites ecológicos de nuestro planeta, también ofrece un argumento que responde a la tesis de Malthus, la cual afirma que la capacidad de crecimiento de la población y la satisfacción de sus necesidades exceden infinitamente la capacidad de la Tierra para producir los recursos requeridos. Sin embargo, diferentes voces también señalan los límites de la idea de Malthus, que, como lo expresa Garrard (2012), pasa por alto que el concepto de la capacidad de carga en los ecosistemas habitados por humanos no considera que la forma de aprovisionamiento y transformación de los recursos de una sociedad no se limita a lo que hay en su territorio, sino que está siempre mediada por poderes económicos, políticos y militares. Esto significa que a medida que la población humana crece y sus necesidades (básicas o creadas) aumentan, la presión sobre los ecosistemas y el impacto ambiental se van desplazando o postergando gracias a eventos como la colonización de nuevos territorios, la esclavitud, el uso de ciertas tecnologías y el outsourcing, entre otras estrategias que desplazan el deterioro o la entropía del medio hacia otros lugares o en el tiempo. Es decir, la anexión de nuevos territorios, la mano de obra barata o esclavizada o el uso de abonos derivados del petróleo dilatan los límites de crecimiento de unas sociedades al usar los recursos que otras requieren para sus necesidades básicas.

La aspiración de conquistar otros planetas en Interestelar escenifica la colonización en un espacio deshabitado, y la tecnología que se usa es también una muestra de estas relaciones de apropiación. Muchas de estas estrategias, como la explotación laboral, colonización, desplazamientos forzados, etc., son posibles gracias a la intermediación de la tecnología (especialmente las tecnologías fósiles). Así, por ejemplo, la construcción de plantas desalinizadoras en regiones áridas, que si bien ayuda a garantizar el acceso a agua apta para el consumo humano, puede servir también para relativizar la gravedad que significan la desaparición y explotación de fuentes de agua dulce en el mundo y postergar acciones más fuertes para su conservación.

O la digitalización de lugares de trabajo, que si bien lleva al ahorro de papel y a la reducción de la deforestación en un sitio, intensifica la demanda de tecnología, como celulares o computadores, lo que termina ejerciendo más presión sobre fuentes minerales y de energía en sitios invisibles para el consumidor. David Harvey (2014) ha dicho que el capitalismo realmente no soluciona las crisis que genera, sino que solo las mueve geográficamente. A esto se podría agregar que no solo se mueven en el espacio, sino también en el tiempo, de una generación a otra, la cual deberá lidiar y asumir los 
efectos ambientales de la polución, alteración de los ecosistemas y otros eventos que son estructurales al modelo de crecimiento económico actual.

Esta continua degradación ambiental no ha sido una barrera para la creación de riqueza actual; diferentes autores (como Rosa Luxemburgo y Alf Hornborg, etc.) proponen que para superar cada crisis inherente a la producción de capital, es necesaria la apropiación de más espacio y tiempo, que encierran recursos y fuerza de trabajo para producir más valor.

Antes que soñar con soluciones provistas por tecnología avanzada a problemas de sustentabilidad ecológica, deberíamos reconocer la mayoría de las tecnologías modernas como estrategias sociales para desplazar problemas (cargas laborales y ambientales) a áreas donde el trabajo y la degradación ambiental son menos $\operatorname{costosos}^{5}$ (Hornborg, 2016).

Así, el mercado global tiende a desplazar las cadenas de producción a países más pobres y, por lo tanto, con políticas ambientales más laxas; dichos países, en muchos casos, pretenden atraer capitales extranjeros y generar mayores márgenes de riqueza a menores costos de producción, posibles gracias a una mayor abundancia de recursos, más la falta de legislación y estándares de protección ambientales.

La crisis que atraviesa el planeta Tierra en Interestelar es tan profunda que amenaza la reproducción misma de la vida humana. Esta realidad está representada en la enfermedad de los niños y especialmente en la muerte del primer nieto de Cooper, de la cual se entera en un video porque está en su misión espacial. En este caso, la crisis no solo demanda la apropiación de más espacio fuera de nuestra limitada atmósfera; los planetas conocidos hasta el momento no permiten la vida o el asentamiento humano sin mediación de la tecnología; por lo tanto, no es posible la conformación de una sociedad humana en ellos sin terminar de extraer y modificar a gran escala los ya menguados recursos terrestres.

La profundidad de la emergencia ambiental genera una nueva crisis, a su vez, en las maneras mismas de extracción y apropiación de recursos, pues el tiempo se termina: mayor mortalidad y esterilidad impiden que haya nuevas generaciones, fuerza de trabajo, y el espacio terrestre en la atmósfera ya no crea valor (los cultivos se queman, no hay tierras que produzcan o que se regeneren por la erosión generalizada). La película halla una respuesta a este callejón al encontrar la forma de apropiarse de una tercera dimensión, de la fuerza de gravedad, para moldear y expandir el tiempo y el espacio disponibles a fin de que sean integrados y explotados. Más que invalidarla, la película actualiza la pregunta maltusiana cuando señala los límites ambientales de este planeta, pero también apunta el papel de la tecnología 
para evadir o desplazar esas cargas ambientales a otros lugares y distribuirlas inequitativamente en el tiempo al pasárselas a generaciones futuras.

\section{Tecnología y cornucopia}

El filósofo esloveno Slavoj Žižek comenta que en la trilogía de Batman, hecha también por Nolan, la mentira aparece como un mal necesario para mantener el orden establecido en una sociedad (El Hombre que Ríe, 2021). En esta ocasión, también la mentira aparece como necesaria para llevar a cabo la misión de exploración espacial, que, luego se descubre, resulta ser una misión sin retorno. Además, alrededor de esta mentira se dibuja la narrativa de sacrificio que se basa en la separación padre-hija, o la separación del padre de su núcleo familiar, en nombre de la ciencia y para la continuación de la vida humana.

La manipulación de la fuerza de gravedad termina siendo representada como un reto intelectual, casi una convicción; nunca le muestra al espectador los mecanismos y medios materiales para moldear barrios enteros y así ahorrar espacio en una colonia, ni explica materialmente cómo unas construcciones de esas dimensiones son posibles en un mundo marcado por la escasez y en una misión en medio de la clandestinidad dentro de un Estado represivo. Cuando Murph conoce la verdad sobre la misión en la que participa su padre (es decir, que nunca se planeó su regreso), ella se recupera para insistir en resolver el problema teórico en su tablero, lo que les dará más tiempo a quienes viven en la Tierra y, así, poder traer de vuelta a su padre; esto introduce la perspectiva cornucopiana, en la cual el conocimiento y la tecnología avanzan y nos ofrecen las soluciones en el momento oportuno, o al menos siguen un desarrollo lineal, un progreso imparable, si se les inyectan suficiente trabajo y recursos.

La narrativa cornucopiana que se teje en Interestelar parece posible por el avance imparable de la tecnología, cuya materialidad se da por sentada. La tecnología aparece en una escena cargada de positivismo, en medio de la crisis, cuando los protagonistas persiguen un dron que vuela bajo. El dron de origen indio (única mención de otro país en ese futuro postapocalíptico) los lleva eventualmente al grupo clandestino de científicos que integrarían a Cooper a la misión para encontrar un planeta donde el ser humano pueda recuperar la prosperidad de una sociedad, la cual se ha perdido irreparablemente. Vale volver a enfatizar que esta pérdida hace referencia a un modo de vida privilegiado, marcado por la abundancia y su inmediatez, más que la degradación ecológica, y es lo que mueve el impulso explorador y colonizador de la misión científica a la que los Cooper, padre e hija, se unen. 
Esto resuena con la visión cornucopiana que Garrard (2012) define como la idea de que "el dinamismo de las economías capitalistas" basta para proveer las soluciones de las problemáticas ambientales. Para quienes tienen esta perspectiva, la emergencia ambiental y sus manifestaciones no son diferentes a otros problemas históricos del pasado, y se irán solucionando a medida que van surgiendo, pues asumen que al mismo tiempo la riqueza y la tecnología en aumento serían suficientes para tal fin. A diferencia de otras perspectivas cornucopianas, en Interestelar la escasez sí se reconoce como un elemento ecológico, pues presenta los límites inherentes al planeta y los problemas ambientales no son solo fallas administrativas o técnicas; aun así, la causa de la erosión o la crisis ambiental se mantiene velada, no se discute su cambio en las nuevas colonias humanas.

Los límites planetarios se resaltan especialmente cuando hablan de los cultivos y la comida, cada vez más difícil de cosechar y cuya variedad se ha reducido casi exclusivamente al maíz, un maíz que siguen cultivando en gran escala con viejos métodos. Sin embargo, la respuesta de los protagonistas en Interestelar sigue siendo esencialmente cornucopiana: la solución para ellos no es adaptar su consumo y sus prácticas a las nuevas limitaciones ambientales ni reimaginar su forma de habitar el planeta, sino invertir sus esfuerzos en colonizar un nuevo mundo donde reproducir la abundancia del pasado y dejar sin cuestionamientos la trayectoria que los llevó a la crisis ambiental en un primer lugar.

\section{Conclusión}

Para cerrar el análisis puedo plantear que los aspectos culturales que resalta la película Interestelar se concentran en un tipo de organización sociopolítica (las libertades individuales, la iniciativa privada y el Estado-nación) y en comportamientos señalados positivamente, como el estoicismo de los personajes frente a situaciones adversas, la inclinación a la exploración y la fe en la ciencia y la tecnología.

Puede interpretarse que la película asume también una visión dicotómica sobre la cultura y la ciencia; la cultura es retrógrada para la supervivencia humana tomada como el objetivo más alto en el relato y, en contraste, la ciencia es la posición sensata que los personajes deben seguir para lograr su propósito, desconociendo que sus respuestas y motivaciones son asimismo profundamente culturales.

De igual forma, la película propone una visión apolítica de la tecnología en varios niveles. Además de la clandestinidad, las metodologías para desarrollar el proyecto no son discutidas ni tampoco surgen preguntas 
éticas a partir de ellas; las tecnologías se muestran como externas a un mercado internacional de tecnología o relaciones de producción, donde otros países o grupos privilegiados estarían involucrados o compitiendo por acceder a un proyecto de tales condiciones o por acceder a materias primas en un mundo de recursos menguados.

Otro nivel en que se pone la tecnología como apolítica es la adjudicación de un propósito o en qué escenario usarla, pues muestra al espectador una perspectiva de los avances científicos: la manipulación de la fuerza de gravedad nace y es usada con el único objetivo de completar la misión para llevar a los humanos a otros planetas. Así se pueden interpretar la ciencia y sus avances como teleológicos y reafirmantes de la fe en la tecnología, pues no solo suponen que los progresos en estos campos dependen más de la voluntad humana que de otros factores como límites al entendimiento humano o límites materiales, sino que reproducen la premisa cornucopiana, en la que las tecnologías siempre llegan a tiempo para responder a los problemas.

Esta película, como documento cultural, construye discursivamente imaginando las actitudes y valores del ser humano como un agente de cambio, explorador, ingenioso, en busca de cambios para mantener un sistema de valores (libertades individuales, abundancia, etc.) y que se antepone a un ambiente hostil, desligado de cuestiones materiales, creencias y de un hábitat terrestre para lograr sus objetivos. Al respecto de las aspiraciones que proyecta la película, está el desarrollo de tecnología como una herramienta infinita, en cuanto a la provisión de recursos para su desarrollo (también muestra una tecnología independiente del contexto material, la escasez o los intereses políticos); además, es representada como una fuente de soluciones oportunas e imparables que orienta y ayuda a concretar los objetivos y el futuro cornucopiano de los protagonistas.

Estos elementos que exponen una forma concreta de imaginar, aspirar y anticipar el futuro colectivo, aunque no se muestra despojada de emociones, parecen también exponer rasgos de lo que Arjun Appadurai (2013) llama ética de la probabilidad. Esta ética se centra en la atomización de grupos para el desarrollo de un aventurerismo privado, la exploración y ascensión unilateral de Estados Unidos (como representante de la humanidad por defecto), y abandona la posibilidad de rehabilitar o crear con el propósito de restaurar y cuidar el planeta Tierra y a esos otros que se han dejado atrás. 


\section{Referencias}

Appadurai, A. (2013). El futuro como hecho cultural. Ensayos sobre la condición global. Fondo de Cultura Económica. https: / / www.fondodeculturaeconomica.com/ Ficha/9786071639523/F

Buschmann, P; Oels, A. (2018). The overlooked role of discourse in breaking carbon lockin: The case of the German energy transition. Wiley Interdisciplinary Reviews: Climate Change. https: / / wires.onlinelibrary.wiley.com/doi/pdf/10.1002/wcc.574

Garrard, G. (2012). Ecocriticism. Routledge. https: / / www.routledge.com/Ecocriticism/ Garrard/p/book/9780415667869

Harvey, D. (2014). Diecisiete contradicciones y el fin del capitalismo [PDF]. Profile Books. Prácticas Constituyentes. https:/ / www.traficantes.net/sites/default/files/pdfs/ Diecisiete\%20contradicciones\%20-\%20Traficantes\%20de\%20Sue\%C3\%B1os.pdf

Hornborg, A. (2016). Global magic. Technologies of appropriation from ancient Rome to Wall Street. Palgrave Macmillan. https:// doi.org/10.1057/9781137567871

Norgaard, M. (2011). Living in denial: climate change, emotions, and everyday life. MIT Press. https: / / doi.org/10.7551/mitpress/9780262015448.001.0001

Skill, K. (2011). Investigar problemas ambientales en antropología social y científica: una aproximación al campo. Avá, Revista de Antropología, (18). https://www.redalyc.org/ articulo.oa?id=1690/169021173005

\section{Películas}

Cuarón, A. [Director]. (2006). Children of men [Cinta cinematográfica]. Co-production Reino Unido-Japón-Estados Unidos, Universal Pictures, Strike Entertainment, Hit y Run Productions, Toho-Towa.

Gray, J. [Director]. (2019). Ad astra [Cinta cinematográfica]. Co-production Estados UnidosBrasil-China, Plan B Entertainment, Regency Enterprises, Keep Your Head Productions, MadRiver Pictures, 20th Century Fox, Regency Enterprises, RT Features, Bona Film Group.

Nolan, C. [Director]. (2014). Interstellar [Cinta cinematográfica]. Warner Bros., Syncopy Production, Paramount Pictures, Legendary Pictures, Lynda Obst Productions.

\section{Videos}

El Hombre que Ríe. (2021, marzo 2). Zizek - El Caballero Oscuro (Subtitulado)

[Video]. YouTube. https: //www.youtube.com/watch?v=BRBsvyK_w9o\&ab_ channel=Elhombrequer\%C3\%ADe

Wisecrack. (2021, febrero 28). Interstellar: is It deep or dumb? [Video]. YouTube. https: / / www.youtube.com/watch?v=f1ZCfmjzUZM 